Article

\title{
Agglomeration-Flotation of Finely Ground Chalcopyrite Using Emulsified Oil Stabilized by Emulsifiers: Implications for Porphyry Copper Ore Flotation
}

\author{
Vothy Hornn ${ }^{1, *}$, Mayumi Ito ${ }^{2}$, Hiromasa Shimada ${ }^{1}$, Carlito Baltazar Tabelin ${ }^{3}{ }^{\oplus}$, Sanghee Jeon ${ }^{2}$, \\ Ilhwan Park ${ }^{2}$ and Naoki Hiroyoshi ${ }^{2}$ \\ 1 Division of Sustainable Resources Engineering, Graduate School of Engineering, Hokkaido University, \\ Sapporo 060-8628, Japan; simada.hiromasa.2525@gmail.com \\ 2 Division of Sustainable Resources Engineering, Faculty of Engineering, Hokkaido University, \\ Sapporo 060-8628, Japan; itomayu@eng.hokudai.ac.jp (M.I.); shjun1121@gmail.com (S.J.); \\ i-park@eng.hokudai.ac.jp (I.P.); hiroyosi@eng.hokudai.ac.jp (N.H.) \\ 3 School of Minerals and Energy Resources Engineering, The University of New South Wales, \\ 2052 Sydney, NSW, Australia; c.tabelin@unsw.edu.au \\ * Correspondence: vothytalis1102@yahoo.com; Tel.: +81-011-706-6315
}

Received: 24 June 2020; Accepted: 7 July 2020; Published: 8 July 2020

check for updates

\begin{abstract}
Flotation is the conventional method for processing porphyry copper deposits, one of the most economically important sources of copper $(\mathrm{Cu})$ worldwide. The rapidly decreasing grade of this type of $\mathrm{Cu}$ ore in recent years, however, presents serious problems with fine particle recovery using conventional flotation circuits. This low recovery could be attributed to the low collision efficiency of fine particles and air bubbles during flotation. To improve collision efficiency and flotation recovery, agglomeration of finely ground chalcopyrite $\left(\mathrm{CuFeS}_{2}\right)\left(\mathrm{D}_{50}=3.5 \mu \mathrm{m}\right)$ using emulsified oil stabilized by emulsifiers was elucidated in this study. Specifically, the effects of various types of anionic (sodium dodecyl sulfate (SDS), potassium amyl xanthate (KAX)), cationic (dodecyl amine acetate (DAA)), and non-ionic (polysorbate 20 (Tween 20)) emulsifiers on emulsified oil stability and agglomeration-flotation efficiency were investigated. When emulsifiers were added, the average size of agglomerates increased, resulting in higher $\mathrm{Cu}$ recovery during flotation. This dramatic improvement in flotation efficiency could be attributed to the smaller oil droplet size in emulsified oil and their higher stability in the presence of emulsifiers. The utilization of emulsifiers during agglomeration-flotation not only lowered the required agitation strength for agglomeration but also shortened the agglomeration time, both of which made the process easier to incorporate in existing flotation circuits.
\end{abstract}

Keywords: agglomeration; emulsified oil; emulsifiers; flotation; fine chalcopyrite

\section{Introduction}

Porphyry copper deposits are economically the most important source of copper $(\mathrm{Cu})$ worldwide because of their wide distribution and enormous volume of minable ore materials. Some porphyry copper deposits have over 1 billion metric tons ( $t$ ) of ore at $>0.5 \%$ of $\mathrm{Cu}$ [1], and many of these deposits typically contain other valuable metals aside from $\mathrm{Cu}$, such as gold $(\mathrm{Au})$ and molybdenum $(\mathrm{Mo})$, making their exploitation economically attractive. For example, the largest open pit porphyry copper mine in the world—the Escondida mine in Chile-processes a porphyry copper deposit containing $0.25 \mathrm{~g} / \mathrm{t} \mathrm{Au}$ and $0.0062 \mathrm{wt} \% \mathrm{Mo}$ [2]. The conventional technique used to recover valuable minerals 
from porphyry copper ores is flotation, a technique whereby fine particles of $\mathrm{Cu}$-bearing minerals like chalcopyrite $\left(\mathrm{CuFeS}_{2}\right)$ are separated from gangue minerals and collected by bubbles after surface modifications using emulsifiers called collectors [3,4]. Flotation, including its concept of using bubbles to induce separation of materials with different surface wettability properties, is a popular and widely used technique not only in the mineral processing and coal cleaning/washing industries but also in electronic waste and plastic recycling industries [5-11].

Despite its popularity and widespread application, one major drawback of flotation is the dramatic drop in its efficiency when particle sizes become very small [12]. The low recovery of fine particles during flotation is attributed to the low collision probability between fine mineral particles and air bubbles [13-15]. Many studies have suggested ways to overcome the poor fine particle recovery during flotation using two approaches: (1) bubble size reduction, and (2) particle aggregation. Column flotation [16], microbubble flotation [17], electro-flotation [18], and dissolved air flotation [19] are some examples of bubble size reduction approaches, while particle aggregation strategies include shear flocculation [20], carrier flotation [21], polymer flocculation [22], and oil agglomeration [13].

All of these techniques have their own advantages and disadvantages, but from the perspective of economics, oil agglomeration - a method to increase the apparent particle size using oil as a "bridging" liquid under intense mixing - is considered as one of the most promising techniques for industrial-scale applications. Oil is relatively inexpensive, and the process could be easily integrated into existing flotation circuits. Although oil agglomeration has been extensively studied for coal cleaning [23,24], there is still one serious issue with this technique when applied to porphyry copper ores: the amount of oil required remains huge (up to $5-10 \%$ of total weight of coal for agglomeration-screening technique or around $0.1-1.0 \%$ for agglomeration-flotation technique) [25]. To address this problem, agglomeration-flotation using emulsified oil instead of simply adding oil during the agglomeration step has been proposed [26-28]. Emulsification of oil reduces the size of oil droplets, which lowers the amount of oil required for agglomeration dramatically.

With the decreasing grade and quality of porphyry copper deposits, flotation is increasingly becoming less efficient because of the smaller grain size of $\mathrm{Cu}$-bearing minerals that require finer grinding for sufficient liberation [29]. As a result, fine particles cannot be recovered by conventional flotation, resulting in loss of valuable minerals. Trahar [15], for example, studied chalcopyrite-quartz flotation and reported that the recovery of chalcopyrite was lower when the median particle size decreased from 20 to $3 \mu \mathrm{m}$. In the previous work of the authors, agglomeration-flotation using emulsified oil instead of directly adding oil during the agglomeration step was conducted using finely ground chalcopyrite [4]. The results showed that the stability of emulsified oil was relatively short, so strong agitation strength is required to disperse oil droplets into water, maintain the small size of oil droplets, and facilitate particle agglomeration [4]. This strong agitation during agglomeration requires high energy, which make the process costly and problematic when integrated into actual flotation circuits.

One way to address this issue is to stabilize emulsified oil using emulsifiers during agglomeration-flotation. Emulsifiers are compounds that lower the surface tension between two immiscible liquids and have been reported to enhance not only the formation of small oil droplets but also stabilize them in aqueous medium [30]. To the best of our knowledge, agglomeration-flotation using emulsified oil stabilized by emulsifiers on finely ground chalcopyrite has never been studied before. In this study, the effects of emulsified oil stabilized by various types of emulsifiers on agglomeration and flotation of finely ground chalcopyrite were investigated. 


\section{Materials and Methods}

\subsection{Materials}

The chalcopyrite sample used in this study was obtained from Copper Queen Mine, Arizona, USA. The sample was characterized by X-ray fluorescence (XRF) (EDXL300, Rigaku Corporation, Tokyo, Japan), X-ray powder diffraction (XRD, MultiFlex, Rigaku Corporation, Tokyo, Japan), and scanning electron microscopy (SEM, SM-IT200, JEOL Ltd., Tokyo, Japan).

The sample was crushed using a jaw crusher (1023-A, Yoshida Manufacturing Co., Ltd, Sapporo, Japan) and ground by a vibratory disc mill (RS100, Retsch Inc., Haan, Germany), then screened to obtain a size fraction of less than $75 \mu \mathrm{m}$. The ground sample $(<75 \mu \mathrm{m})$ was ground again in the vibratory disc mill to obtain fine particles. The particle size distribution of the chalcopyrite sample used in this study was measured in water after ultrasonication using laser diffraction (Microtrac®MT3300SX, Nikkiso Co., Ltd., Tokyo, Japan).

Potassium amyl xanthate (KAX) (Tokyo Chemical Industry Co., Ltd., Tokyo, Japan), kerosene (Wako Pure Chemical Industries, Ltd., Osaka, Japan), methyl isobutyl carbinol (MIBC) (Tokyo Chemical Industry Co., Ltd., Tokyo, Japan), sodium dodecyl sulfate (SDS) (Tokyo Chemical Industry Co., Ltd., Japan), dodecyl amine acetate (DAA) (Tokyo Chemical Industry Co., Ltd., Tokyo, Japan), and polysorbate 20 (Tween20) (Tokyo Chemical Industry Co., Ltd., Tokyo Japan) were used in this study. The chemical structures of the four emulsifiers (SDS, KAX, DAA, and Tween 20) used in this study are shown in Figure 1.

(a)<smiles>CCCCCCCCCCCCOS(=O)(=O)[OH2+]</smiles>

(c)

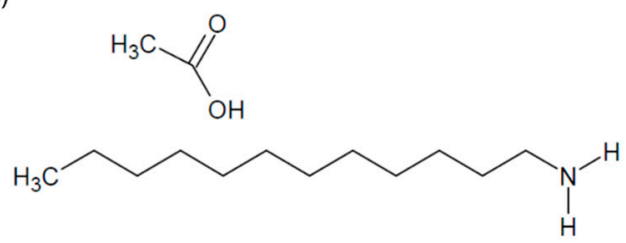

(b)<smiles>[3H][S+]C(=S)OCCCCC</smiles>

(d)

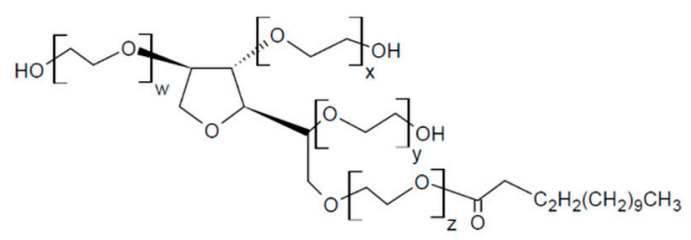

Figure 1. Chemical structures of emulsifiers: (a) SDS, (b) KAX, (c) DAA, and (d) Tween 20.

\subsection{Methods}

\subsubsection{Preparation of Emulsified Oil with Emulsifiers}

Anionic (SDS, KAX), cationic (DAA), and non-ionic (Tween 20) emulsifiers were used as emulsifying reagents. First, $10 \mathrm{~mL}$ of kerosene was mixed with $40 \mathrm{~mL}$ of deionized (DI) water, and then $0.1 \mathrm{~g}$ of the emulsifiers (SDS, KAX, DAA, or Tween 20) was added (i.e., concentration of emulsifiers, 2000 ppm). Emulsification of the mixture was then carried out before agglomeration using an ultrasonic homogenizer (ULTRA-TURRAX, IKA, Königswinter, Germany) for 60 s. After emulsification, oil droplet size was measured using laser diffraction.

\subsubsection{Stability Tests of Emulsified Oil}

Stability tests of emulsified oil containing different emulsifiers were carried out to evaluate the stability of the suspensions [31]. The emulsified oil after emulsification was equilibrated for 5 min until the bubble foams disappeared. Then, $50 \mathrm{~mL}$ of emulsified oil was centrifuged at $3500 \mathrm{rpm}$ for $20 \mathrm{~min}$. The volume ratios of oil and emulsion layer were calculated by measuring the thickness of oil layer. 


\subsubsection{KAX Conditioning and Agglomeration}

Two conditions were evaluated during KAX conditioning and agglomeration as follows:

(a) Agglomeration at an agitation speed of $1000 \mathrm{rpm}$

i. KAX conditioning: Before agglomeration, $20 \mathrm{~g}$ of sample $\left(\mathrm{D}_{50}=3.5 \mu \mathrm{m}\right)$ was suspended in $400 \mathrm{~mL}$ of distilled water and then conditioned with the surface modifier, KAX (200 g/t), to improve hydrophobicity for $5 \mathrm{~min}$ at $1000 \mathrm{rpm}$ in the flotation cell (FT-1000, Heiko, Tokyo, Japan).

ii. Agglomeration: After conditioning, emulsified oil ( $15 \mathrm{~L}$ kerosene/t sample, with and without surfactant) was added to the suspension, and agitation was carried out at $1000 \mathrm{rpm}$ for $30 \mathrm{~min}$ in the flotation cell.

(b) Agglomeration at an agitation speed of $15,000 \mathrm{rpm}$

i. KAX conditioning: Before agglomeration, $20 \mathrm{~g}$ of sample $\left(\mathrm{D}_{50}=3.5 \mu \mathrm{m}\right)$ was suspended in $400 \mathrm{~mL}$ of distilled water and then conditioned with the surface modifier, KAX ( $200 \mathrm{~g} / \mathrm{t})$ for $5 \mathrm{~min}$ at $1000 \mathrm{rpm}$ in the flotation cell.

ii. Agglomeration: After conditioning, the suspension was transferred to an agglomeration vessel (high speed mixer with a s-shaped impeller, SPB-600J, Cuisinart, Stamford, CT, USA; fixed rotation speed of 15,000 rpm), emulsified oil (15 L kerosene/t sample, with and without surfactant) was added, and agitation was carried out for $30 \mathrm{~min}$. Suspension after agglomeration was then transferred to a $500 \mathrm{~mL}$ flotation cell.

The emulsified oil with emulsifiers was allowed to equilibrate for 5 min after emulsification prior to its use in the agglomeration step. In contrast, emulsified oil without any surfactant was used immediately because of the short stability of suspension. After agglomeration, the particle size distribution was measured by laser diffraction.

\subsubsection{Flotation Tests}

Flotation was carried out using a mechanical flotation machine (FT-1000, Heiko, Tokyo, Japan). MIBC $(25 \mu \mathrm{L} / \mathrm{L})$ was added as a frother, and the suspension was stirred for 3 min with an impeller speed of $1000 \mathrm{rpm}$. Air was then injected into the suspension at a flow rate of $1 \mathrm{~L} / \mathrm{min}$, and flotation was carried out (total flotation time of $10 \mathrm{~min}$ ). Froths were collected at predetermined time intervals, and both froth products and tailings were weighed after drying at $105^{\circ} \mathrm{C}$ for $24 \mathrm{~h}$, and their chemical compositions were determined by XRF.

\section{Results and Discussion}

\subsection{Characteristics of Chalcopyrite Samples}

Chalcopyrite sample used in this study were characterized by XRF, XRD, SEM-EDX, and laser diffraction sizer. The chemical composition of the chalcopyrite sample (XRF) is shown in Table 1. Figure $2 \mathrm{a}, \mathrm{b}$ shows the results of XRD and SEM-EDX analysis, respectively, of finely ground chalcopyrite. XRD analysis showed that the sample was mainly composed of chalcopyrite with minor amounts of actinolite $\left(\mathrm{Ca}_{2} \mathrm{Mg}_{3} \mathrm{Fe}_{2} \mathrm{Si}_{8} \mathrm{O}_{22}(\mathrm{OH})_{2}\right)$ and quartz. Figure 3 shows the particle size distributions of finely ground chalcopyrite (median particle diameter $\left(D_{50}\right)$ of $3.5 \mu \mathrm{m}$ ), which was used in this study.

Table 1. Chemical composition of chalcopyrite sample.

\begin{tabular}{lcccccc}
\hline Elements & $\mathbf{C u}$ & Fe & S & Zn & Si & Ca \\
\hline $\mathrm{wt}^{\circ} \%$ & 26 & 27 & 26 & 0.8 & 6 & 2 \\
\hline
\end{tabular}



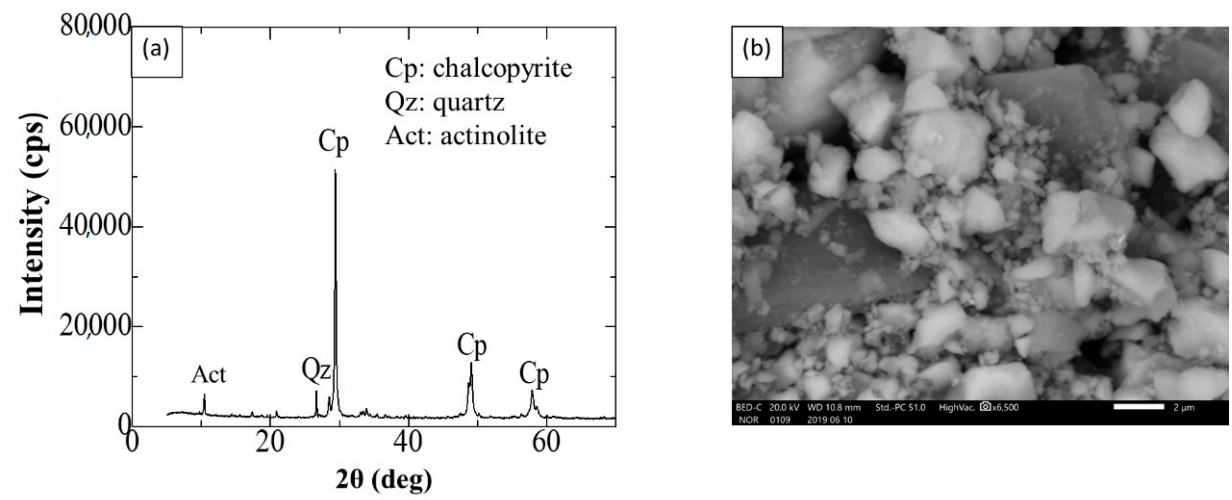

Figure 2. Chalcopyrite sample: (a) XRD patterns, and (b) SEM image.

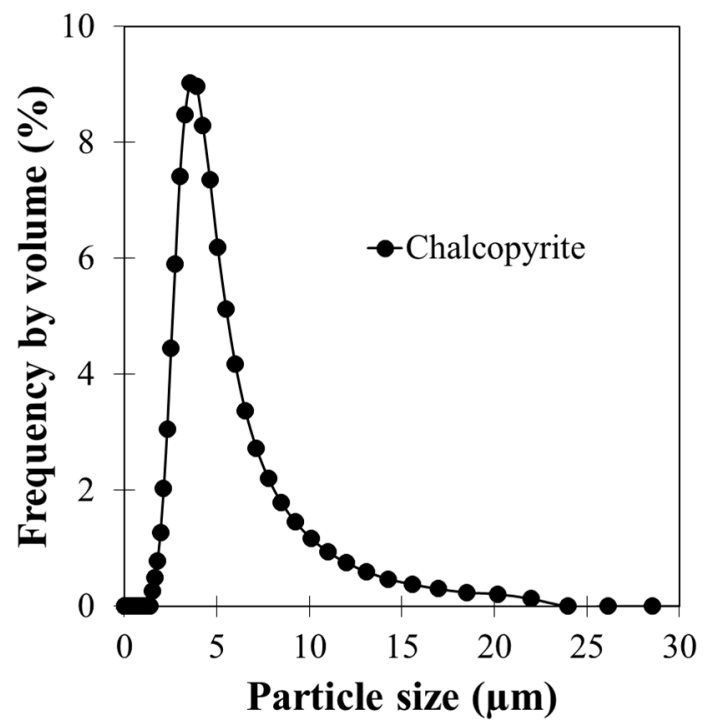

Figure 3. Particle size distribution of chalcopyrite sample.

\subsection{Effects of Emulsifiers on Emulsified Oil Droplet Size and Stability}

Anionic emulsifiers (SDS, KAX), cationic surfactant (DAA), and non-ionic surfactant (Tween 20) were used as emulsifying agents during the preparation of emulsified oil. These emulsifiers were chosen to represent three main types of flotation collector that have great potential to be used as emulsifying agents. Figure 4 shows the size distribution of oil droplets with and without addition of emulsifiers, and the results indicate that the mode size of oil droplets became smaller with emulsifiers. The smaller oil droplet generated in the presence of emulsifiers could be attributed to the reduction in interfacial tension of oil-water [32]. In the previous study of the authors [4], emulsified oil was added to the agglomeration vessel immediately because emulsified oil without surfactant was unstable. In a commercial plant, stability of emulsified oil is important to maintain the small size of oil droplets for oil agglomeration. To check the stability of the suspensions, stability tests were carried out. In this test, centrifugation was used to accelerate oil droplet coalescence, and because the thickness of oil layer relies on ease of coalescence and oil droplet size, this technique could be used to estimate the stability of emulsion. The volume ratios of oil and emulsion layers are shown in Figure 5. The volume of the oil layer after centrifugation was smaller when emulsifiers were present, indicating that these compounds were effective in stabilizing oil droplets and prolonging the usability of emulsified oil. Chen and Tao [32] defined the stability of an emulsion as the resistance by the dispersed oil droplets against coalescence and noted that emulsifying agents maintain the emulsion by forming a thin interfacial film between the two liquids that minimize contact, coalescence, and aggregation of the internal dispersed phase. 


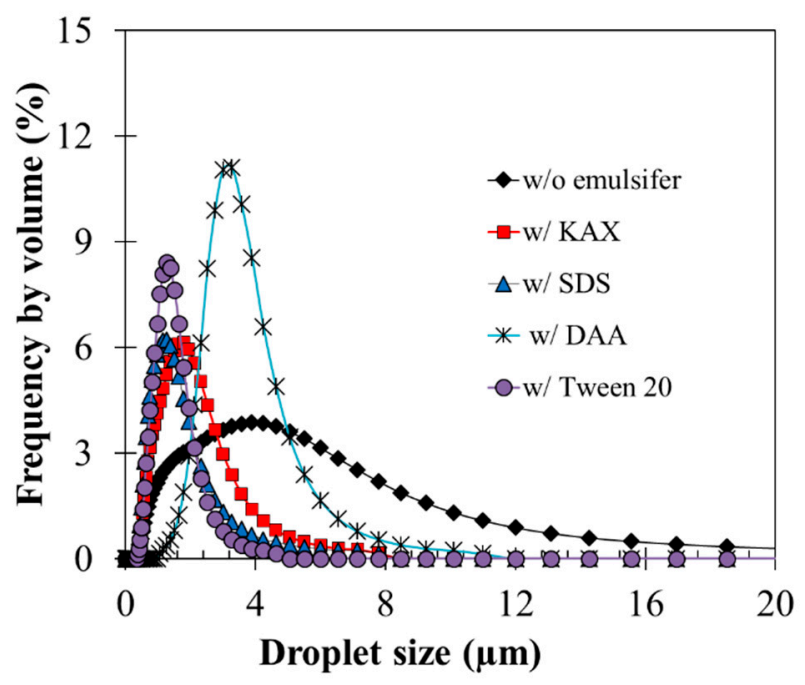

Figure 4. Size distribution of oil droplets after emulsification with and without addition of emulsifiers.

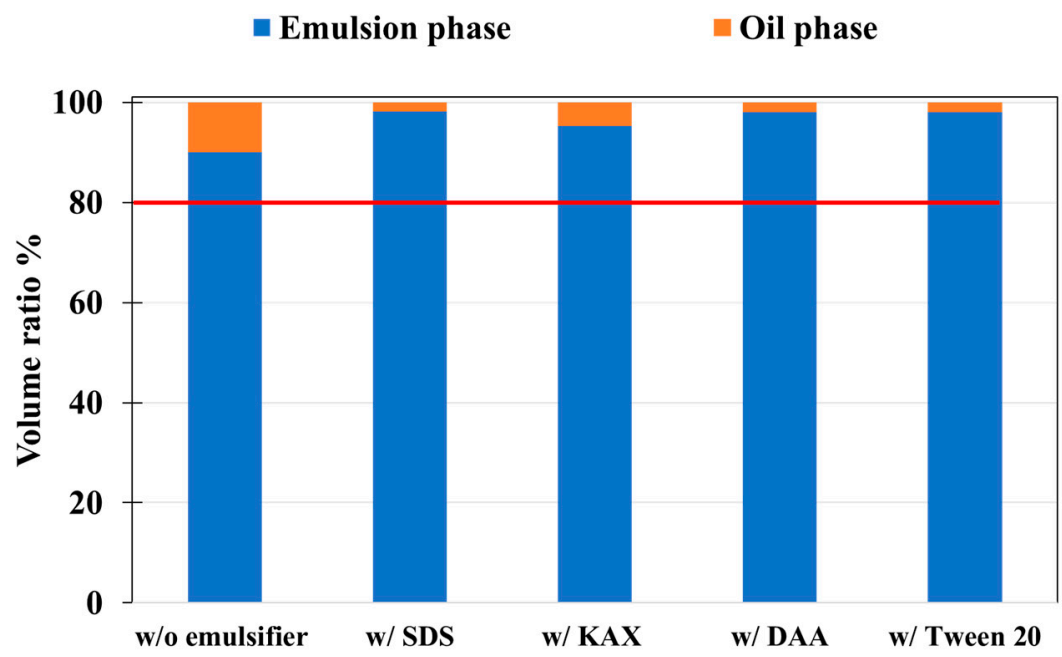

Figure 5. Volume ratio of oil and emulsion layers with and without emulsifiers after emulsification and centrifugation. Note that the red line indicates volume ratio without emulsification ( $80 \%$ water, $20 \%$ oil).

\subsection{Effects of Emulsifiers on Agglomeration}

In the previous section, SDS, KAX, DAA, and Tween 20 were shown to reduce the size of oil droplets and sustain the stability of emulsified oil. The effects of theses emulsifiers on agglomeration of chalcopyrite were investigated. Agglomeration in this study consisted of two stages: (1) conditioning in the flotation cell with $200 \mathrm{~g} / \mathrm{t}$ of KAX, and (2) agglomeration using emulsified oil containing $2000 \mathrm{ppm}$ of emulsifier $(15 \mathrm{~L}$ kerosene/t). Figure 6 shows the apparent particle size distribution after agglomeration (1000 or 15,000 rpm for $30 \mathrm{~min}$ ). The results showed that when SDS, KAX, and DAA were used, the mode size of agglomerate increased more than that without emulsifiers even at a high agitation speed $(15,000 \mathrm{rpm})$. As shown in Figure 4, the droplet size of emulsified oil containing emulsifiers were relatively smaller than that without emulsifiers. When the size of oil droplets decreased, the number of droplets in the agitator increased. Because the frequency of collisions of the oil droplets and particles during agglomeration is proportional to the number of oil droplets, it is reasonable to deduce that the number of oil droplets attached to particle surfaces increased due to the higher collision probability between oil droplets and particles. Because of this, agglomerate size became bigger when emulsified oil containing emulsifiers were used. 


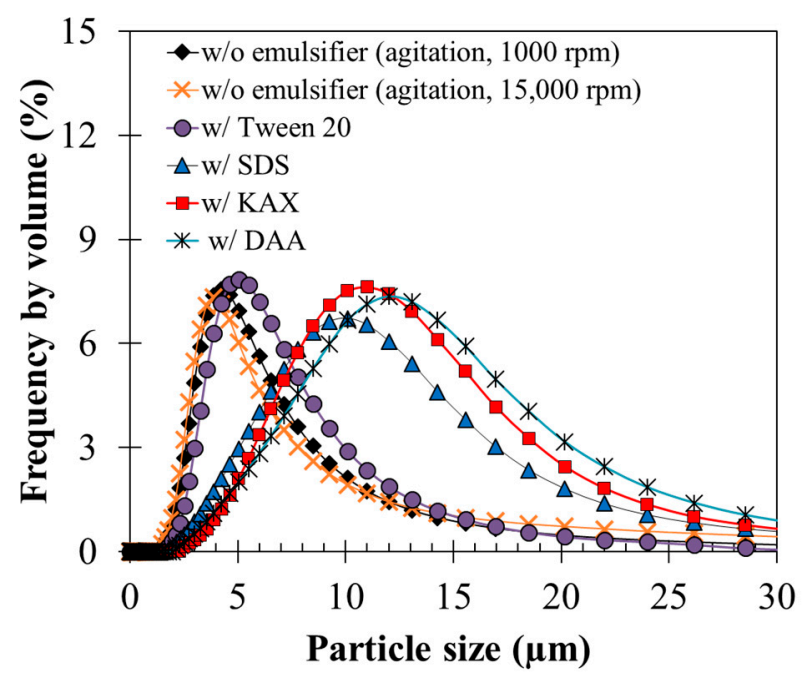

Figure 6. Size distribution after agglomeration (agglomeration conditions: $30 \mathrm{~min}$; $1000 \mathrm{rpm}$ with emulsifiers, 1000 and 15,000 rpm without emulsifiers).

When Tween 20 was used, the mode size of agglomerates was similar to that without surfactant. Agglomeration kinetics and agglomerate size are mainly determined by three processes: (1) particle-particle collision, (2) particle-particle attraction, and (3) decomposition of agglomerate [33]. As shown in Figure 4, the size of droplets with Tween 20 were similar to those with other types of emulsifiers, indicating that the probability of collision between particles and oil droplets may be similar. However, the probability of attraction of particles and oil droplets stabilized by Tween 20 may be lower than those with the other emulsifiers.

\subsection{Effects of Emulsifiers on Flotation}

In this flotation test, agglomeration using emulsified oil with and without emulsifiers was carried out, and flotation of the agglomerates was conducted. Figure 7 shows the $\mathrm{Cu}$ recovery with time (agglomeration conditions: $30 \mathrm{~min}$; $1000 \mathrm{rpm}$ with emulsifiers, 1000 and 15,000 rpm without emulsifiers). Without emulsifiers, $\mathrm{Cu}$ recovery with agglomeration using high agitation strength $(15,000 \mathrm{rpm})$ was higher than that with low agitation strength (1000 rpm), indicating that intense agitation is required for agglomeration-flotation without emulsifiers due to the low stability of emulsified oil.

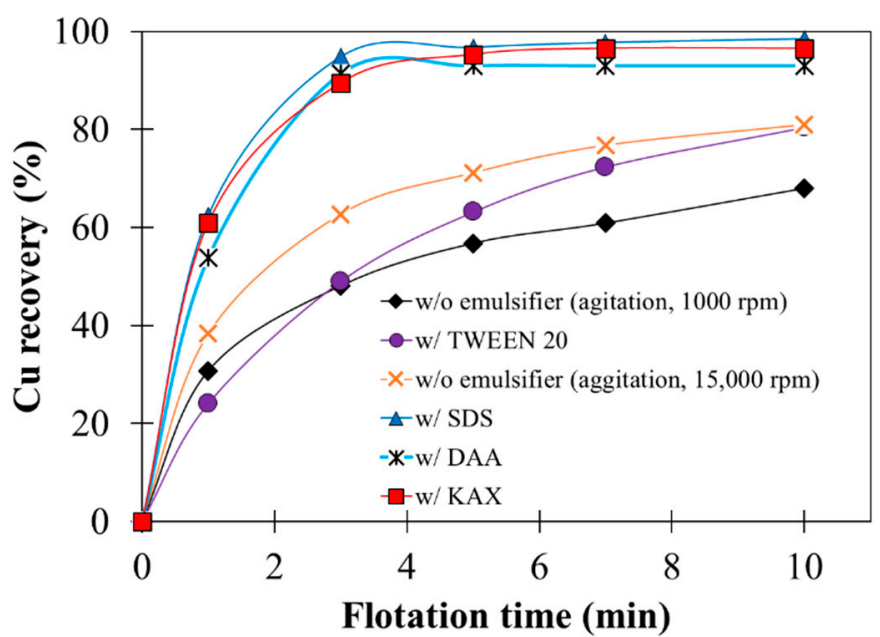

Figure 7. Cu recovery with time (agglomeration conditions: $30 \mathrm{~min}$; $1000 \mathrm{rpm}$ with emulsifiers, 1000 and 15,000 rpm without emulsifiers). 
In the case of agglomeration-flotation with Tween 20, $\mathrm{Cu}$ recovery showed a similar trend with that without emulsifiers. This result is in-line with the result of size distribution of agglomerate; that is, the size of agglomerate using Tween 20 was almost the same as that without emulsifier. The recovery rate of chalcopyrite treated with Tween 20 was lower than those treated with other emulsifiers. Cu recovery rate was affected by the size of agglomerate, as described before and agglomerate size may have been influenced by the affinity between the oil-emulsion and the KAX-adsorbed chalcopyrite surface (KAX was used as the surface modifier to increase the hydrophobicity). Interaction forces between hydrophobic minerals surface and oil emulsion may be determined by the balance of hydrophobic interaction, van der Waals attraction, and steric repulsion of the structure of the hydrophilic head of surfactants. Hydrophilic lipophilic balance (HLB), an indicator of the balance of hydrophilic and hydrophobic groups of surfactants, strongly affects the properties of emulsions, including oil droplet size. HLB values of Tween 20 and SDS are similar, resulting in similar oil droplets sizes [34,35]. However, the size of agglomerate in Tween 20-stabilized emulsion was smaller than that with SDS, indicating that interactions between chalcopyrite and oil droplets with Tween 20 or SDS were different. One possible explanation for the low efficiency of Tween 20 in agglomerating finely ground chalcopyrite is its complex structure consisting of numerous types of hydrophilic heads compared to SDS, as shown in Figure 1. In other words, Tween 20, having hydrophilic heads, may have lowered the hydrophobicity of the oil-emulsion, thereby decreasing the affinity between oil droplets and chalcopyrite.

In the case of agglomeration-flotation with SDS, DAA, and KAX, Cu recovery with agglomeration using these emulsifiers was higher than that in agglomeration with intense agitation strength $(15,000 \mathrm{rpm})$ without emulsifiers. These results indicate that less intense agitation strength (1000 rpm) was sufficient for agglomeration-flotation when emulsifiers were present because of the smaller droplet size and better stability of emulsified oil. This means that when emulsifiers are used, specialized equipment with high agitation strengths are not required, and the process could be easily integrated into existing flotation circuits.

Figure 8 shows the $\mathrm{Cu}$ recovery of agglomerate with SDS at agglomeration times of 15 and $30 \mathrm{~min}$, and the results showed that $\mathrm{Cu}$ recovery was very similar, indicating that agglomeration for 15 min was enough to achieve high $\mathrm{Cu}$ recovery. In other words, utilization of emulsifiers-stabilized oil emulsion could shorten the agglomeration time.

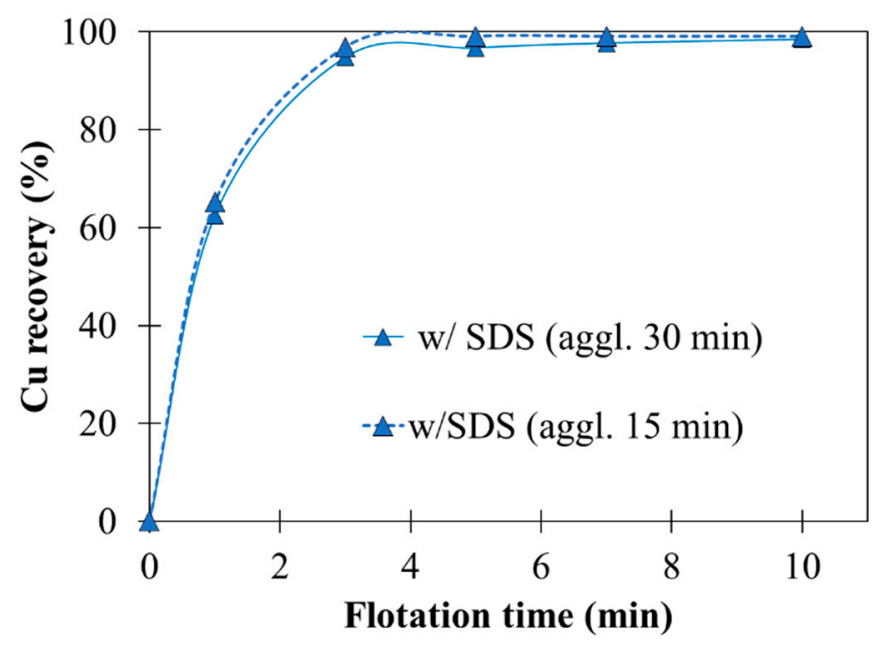

Figure 8. Cu recovery of agglomerate with SDS at agglomeration time of 15 and $30 \mathrm{~min}$. 


\section{Conclusions}

The following conclusions can be drawn from the agglomeration-flotation study using emulsified oil with emulsifiers:

- Addition of emulsifiers (e.g., SDS, KAX, DAA, and Tween 20) reduced the size of oil droplets and maintained the stability of emulsified oil longer.

- Addition of emulsifiers (SDS, KAX, and DAA) to emulsified oil contributed to the formation of bigger agglomerates, thus improving $\mathrm{Cu}$ recovery by agglomeration-flotation even at low agitation strength and shorter agglomeration time.

- When emulsified oil with emulsifiers is used, specialized equipment with higher agitation strength during agglomeration is not required, and thus the process could be easily integrated into existing flotation circuits.

Author Contributions: V.H., M.I., S.J., I.P., and N.H. conceived and designed the experiments; V.H. and H.S. performed the experiments and analyzed the data; V.H. wrote the paper. M.I., C.B.T., S.J., and I.P. reviewed and edited the paper. All authors have read and agreed to the published version of the manuscript.

Funding: This research received no external funding.

Conflicts of Interest: The authors declare no conflict of interest.

\section{References}

1. Brown, T.J.; Bide, T.; Walters, A.S.; Idoine, N.E.; Shaw, R.A.; Hannis, S.D.; Lusty, P.A.J.; Kendall, R.; MacKenzie, A.C. World Mineral Production 2005-09; British Geological Survey: Nottingham, UK, 2011; pp. 29-31.

2. Richards, J.P.; Boyce, A.J.; Pringle, M.S. Geologic Evolution of the Escondida Area, Northern Chile: A Model for Spatial and Temporal Localization of Porphyry Cu Mineralization. Econ. Geol. Bull. Soc. Econ. Geol. 2001, 96, 271-305. [CrossRef]

3. Aikawa, K.; Ito, M.; Segawa, T.; Jeon, S.; Park, I.; Tabelin, C.B.; Hiroyoshi, N. Depression of Lead-Activated Sphalerite by Pyrite via Galvanic Interactions: Implications to the Selective Flotation of Complex Sulfide Ores. Miner. Eng. 2020, 152, 106367. [CrossRef]

4. Hornn, V.; Ito, M.; Shimada, H.; Tabelin, C.B.; Jeon, S.; Park, I.; Hiroyoshi, N. Agglomeration-Flotation of Finely Ground Chalcopyrite and Quartz: Effects of Agitation Strength during Agglomeration Using Emulsified Oil on Chalcopyrite. Minerals 2020, 10, 380. [CrossRef]

5. Ito, M.; Saito, A.; Murase, N.; Phengsaart, T.; Kimura, S.; Tabelin, C.B.; Hiroyoshi, N. Development of Suitable Product Recovery Systems of Continuous Hybrid Jig for Plastic-Plastic Separation. Miner. Eng. 2019, 141, 105839. [CrossRef]

6. Ito, M.; Takeuchi, M.; Saito, A.; Murase, N.; Phengsaart, T.; Tabelin, C.B.; Hiroyoshi, N.; Tsunekawa, M. Improvement of Hybrid Jig Separation Efficiency Using Wetting Agents for the Recycling of Mixed-Plastic Wastes. J. Mater. Cycles Waste Manag. 2019, 21, 1376-1383. [CrossRef]

7. Jeon, S.; Ito, M.; Tabelin, C.B.; Pongsumrankul, R.; Kitajima, N.; Park, I.; Hiroyoshi, N. Gold Recovery from Shredder Light Fraction of E-Waste Recycling Plant by Flotation-Ammonium Thiosulfate Leaching. Waste Manag. 2018, 77, 195-202. [CrossRef]

8. Jeon, S.; Ito, M.; Tabelin, C.B.; Pongsumrankul, R.; Tanaka, S.; Kitajima, N.; Saito, A.; Park, I.; Hiroyoshi, N. A Physical Separation Scheme to Improve Ammonium Thiosulfate Leaching of Gold by Separation of Base Metals in Crushed Mobile Phones. Miner. Eng. 2019, 138, 168-177. [CrossRef]

9. Phengsaart, T.; Ito, M.; Azuma, A.; Tabelin, C.B.; Hiroyoshi, N. Jig Separation of Crushed Plastics: The Effects of Particle Geometry on Separation Efficiency. J. Mater. Cycles Waste Manag. 2020, 22, 787-800. [CrossRef]

10. Phengsaart, T.; Ito, M.; Hamaya, N.; Tabelin, C.B.; Hiroyoshi, N. Improvement of Jig Efficiency by Shape Separation, and a Novel Method to Estimate the Separation Efficiency of Metal Wires in Crushed Electronic Wastes Using Bending Behavior and "Entanglement Factor". Miner. Eng. 2018, 129, 54-62. [CrossRef]

11. Seng, S.; Tabelin, C.B.; Makino, Y.; Chea, M.; Phengsaart, T.; Park, I.; Hiroyoshi, N.; Ito, M. Improvement of Flotation and Suppression of Pyrite Oxidation Using Phosphate-Enhanced Galvanic Microencapsulation (GME) in a Ball Mill with Steel Ball Media. Miner. Eng. 2019, 143, 105931. [CrossRef] 
12. Jiangang, F.; Kaida, C.; Hui, W.; Chao, G.; Wei, L. Recovering Molybdenite from Ultrafine Waste Tailings by Oil Agglomerate Flotation. Miner. Eng. 2012, 39, 133-139. [CrossRef]

13. Dai, Z.; Fornasiero, D.; Ralston, J. Particle-Bubble Collision Models-a Review. Adv. Colloid Interface Sci. 2000, 85, 231-256. [CrossRef]

14. Miettinen, T.; Ralston, J.; Fornasiero, D. The Limits of Fine Particle Flotation. Miner. Eng. 2010, $23,420-437$. [CrossRef]

15. Trahar, W.J.; Warren, L.J. The Flotability of Very Fine Particles-A Review. Int. J. Miner. Process. 1976, 3, 103-131. [CrossRef]

16. Finch, J.A. Column Flotation: A Selected Review- Part IV: Novel Flotation Devices. Miner. Eng. 1995, 8, 587-602. [CrossRef]

17. Yoon, R.H. Microbubble Flotation. Miner. Eng. 1993, 6, 619-630. [CrossRef]

18. Bhaskar Raju, G.; Khangaonkar, P.R. Electro-Flotation of Chalcopyrite Fines. Int. J. Miner. Process. 1982, 9, 133-143. [CrossRef]

19. Rodrigues, R.T.; Rubio, J. DAF-Dissolved Air Flotation: Potential Applications in the Mining and Mineral Processing Industry. Int. J. Miner. Process. 2007, 82, 1-13. [CrossRef]

20. Warren, L.J. Shear-Flocculation of Ultrafine Scheelite in Sodium Oleate Solutions. J. Colloid Interface Sci. 1975, 50, 307-318. [CrossRef]

21. Rubio, J.; Hoberg, H. The Process of Separation of Fine Mineral Particles by Flotation with Hydrophobic Polymeric Carrier. Int. J. Miner. Process. 1993, 37, 109-122. [CrossRef]

22. Sresty, G.C.; Somasundaran, P. Selective Flocculation of Synthetic Mineral Mixtures Using Modified Polymers. Int. J. Miner. Process. 1980, 6, 303-320. [CrossRef]

23. Alonso, M.I.; Valdés, A.F.; Martínez-Tarazona, R.M.; Garcia, A.B. Coal Recovery from Coal Fines Cleaning Wastes by Agglomeration with Vegetable Oils: Effects of Oil Type and Concentration. Fuel 1999, 78, 753-759. [CrossRef]

24. Slaghuis, J.H.; Ferreira, L.C. Selective Spherical Agglomeration of Coal. Fuel 1987, 66, 1427-1430. [CrossRef]

25. Laskowski, J.S.; Liu, Q.; Bolin, N.J. Flotation of Sulphide Minerals 1990 Polysaccharides in Flotation of Sulphides. Part I. Adsorption of Polysaccharides onto Mineral Surfaces. Int. J. Miner. Process. 1991, 33, 223-234. [CrossRef]

26. Bensley, C.N.; Swanson, A.R.; Nicol, S.K. The Effect of Emulsification on the Selective Agglomeration of Fine Coal. Int. J. Miner. Process. 1977, 4, 173-184. [CrossRef]

27. Van Netten, K.; Moreno-Atanasio, R.; Galvin, K.P. Fine Particle Beneficiation through Selective Agglomeration with an Emulsion Binder. Ind. Eng. Chem. Res. 2014, 53, 15747-15754. [CrossRef]

28. Sahinoglu, E.; Uslu, T. Use of Ultrasonic Emulsification in Oil Agglomeration for Coal Cleaning. Fuel 2013, 113, 719-725. [CrossRef]

29. Johnson, N.W. Liberated 0-10 $\mu \mathrm{m}$ Particles from Sulphide Ores, Their Production and Separation-Recent Developments and Future Needs. Miner. Eng. 2006, 19, 666-674. [CrossRef]

30. Stang, M.; Karbstein, H.; Schubert, H. Adsorption Kinetics of Emulsifiers at Oil-Water Interfaces and Their Effect on Mechanical Emulsification. Chem. Eng. Process. Process Intensif. 1994, 33, 307-311. [CrossRef]

31. Chen, G.; Tao, D. An Experimental Study of Stability of Oil-Water Emulsion. Fuel Process. Technol. 2005, 86, 499-508. [CrossRef]

32. Oh, S.G.; Shah, D.O. Effect of counterions on the interfacial tension and emulsion droplet size in the oil/water/dodecyl sulfate system. J. Phys. Chem. 1993, 97, 284-286. [CrossRef]

33. Darelius, A.; Rasmuson, A.; Björn, I.N.; Folestad, S. High shear wet granulation modelling-a mechanistic approach using population balances. Powder Technol. 2005, 160, 209-218. [CrossRef]

34. Kunieda, H.; Hanno, K.; Yamaguchi, S.; Shinoda, K. The Three-Phase Behavior of a Brine/Ionic Surfactant/Nonionic Surfactant/Oil System: Evaluation of the Hydrophile-Lipophile Balance (HLB) of Ionic Surfactant. J. Colloid Interface Sci. 1985, 107, 129-137. [CrossRef]

35. Kunieda, H.; Ishikawa, N. Evaluation of the Hydrophile-Lipophile Balance (HLB) of Nonionic Surfactants. II. Commercial-Surfactant Systems. J. Colloid Interface Sci. 1985, 107, 122-128. [CrossRef]

(C) 2020 by the authors. Licensee MDPI, Basel, Switzerland. This article is an open access article distributed under the terms and conditions of the Creative Commons Attribution (CC BY) license (http://creativecommons.org/licenses/by/4.0/). 